\title{
Long-term effects of intravitreal ranibizumab treatment on retinal ganglion cell complex and choroidal thickness
}

\author{
Akin Cakır ${ }^{*}$, Sercan Koray Sagdıc ${ }^{2}$, Eyup Duzgun ${ }^{3}, B_{\text {Brak Erden }}{ }^{1}$, Ali Ayata ${ }^{4}$ and Melih Hamdi Unal ${ }^{5}$ \\ ${ }^{1}$ Okmeydani Training and Research Hospital, Department of Ophthalmology, Istanbul, Turkey \\ ${ }^{2}$ Kilis Government Hospital, Department of Ophthalmology, Kilis, Turkey \\ ${ }^{3}$ Sisli Hamidiye Etfal Training and Research Hospital, Department of Ophthalmology, Istanbul, Turkey \\ ${ }^{4}$ Haydarpasa Sultan Abdülhamid Training and Research Hospital, Department of Ophthalmology, Istanbul, Turkey \\ ${ }^{5}$ Private Practitioner, Istanbul, Turkey
}

\begin{abstract}
Background: To evaluate the long-term effects of intravitreal ranibizumab treatment on both choroidal and retinal layers thicknesses using spectral domain optical coherence tomography (SD-OCT) and Enhanced Depth Imaging (EDI) mode.

Methods: Thirty-two eyes of 27 patients with classic choroidal neovascularization that have been undergoing intravitreal 0.5 mg ranibizumab injections for a minimum of 2-year follow up were enrolled as the study group. Age and sex matched 31 eyes of 17 nonneovascular age-related macular degeneration subjects constituted the control group. Thickness of retinal layers measured by the program embedded in SD-OCT. Choroidal images were obtained by SD-OCT with EDI mode by the same certified operator.

Results: The mean injection number of the study group was $12.1 \pm 4.0$. The mean follow-up time was $3.6 \pm 1.6$ years. The mean subfoveal choroidal thickness values tended to be lower in ranibizumab treated eyes than controls, but difference was not statistically significant $(184 \pm 75.5 \mu v s .200 .8 \pm 60.2 \mu ; \mathrm{p}: 0.336)$. The study and control groups' mean retinal thickness values were not statistically significant $(250.4 \pm 29.4 \mu$ vs. $249.7 \pm 15.2 \mu$; p:0.906). The mean ganglion cell layer (GCL), internal plexiform layer (IPL) and ganglion cell complex (GCC) values of ranibizumab treated eyes were found to be statistically significantly lower than controls ([21.06 \pm $8.03 \mu$ vs. $24.6 \pm 5 \mu ;$ p:0.036], [24.5 $\pm 7.8 \mu$ vs. $29.8 \pm 3.8 \mu ;$ p:0.001], [64.1 $\pm 16.5 \mu$ vs. $72.9 \pm 8.03 \mu ;$ p:0.010] respectively).

Conclusions: Our study showed that long-term intravitreal ranibizumab treatment was associated with significant reduction in the GCL, IPL and GCC thicknesses. Randomized prospective studies must be conducted to determine if any difference exits between anti-VEGF agents or if this thinning induces any damage in the function of the retinal ganglion cells.
\end{abstract}

\section{Introduction}

Neovascular age-related macular degeneration (AMD) is the leading cause of vision loss among AMD patients. It is responsible forapproximately $\% 85$ of allvisual impairments in AMD [1]. Fortunately, it is currently treated with intravitreal anti-vascular endothelial growth factor (VEGF) agents with good visual outcomes $[2,3]$. As any other effective therapies; surely, side effects are expected. In that manner several anti-VEGF related complications were reported in the literature [4]. While some of them are related with intravitreal injection procedure, somes are directly related with anti-VEGF drugs. More recently, a novel complicationduring anti-VEGF therapy which is termed as "retinal atrophy" has become a current issue [5] still there is a conflict on the definition of the atrophy, it can be described as the atrophy of retina pigment epithelium (RPE) and choriocapillaries that is similar to the appearence of de novo geographic atrophy (GA) [6]. Besides, we know that VEGF inhibition also leads to nonperfusion of vessels in the choroid plexus [7], afterwards choriocapillaries and RPE degeneration occurs [8]. A great number of studies investigated the association between anti-VEGF treatment and RPE-choroidal atrophy by using fundus autofluorescence (FAF) or near-infrared autofluorescence, fluorescein angiogram and/or optical coherence tomography (OCT) imagings [6,9-16]. However, there is limited study in the literature looking at the difference in retinal layers thicknesses in neovascular and nonneovascular AMD patients in order to determine the plausible effect of anti-VEGF treatment [17-19]. Unfortunately, all of these studies have investigated the short term effect of anti-VEGF theraphy. In the current study we aimed to evaluate the long-term effects of intravitreal ranibizumab treatment on both choroidal and retinal layers thicknesses using enhanced depth imaging (EDI) OCT (Spectralis; Heidelberg Engineering, Heidelberg, Germany).

\section{Methods}

Thirty-two eyes of 27 patients with classic choroidal neovascularization (CNV) that have been undergoing intravitreal ranibizumab injections for a minimum of 2-year follow up were enrolled as the study group in this case-control study. Age and sex matched 31 eyes of 17 nonneovascular AMD subjects constituted the control

${ }^{\star}$ Correspondence to: Akin Cakır, Okmeydani Training and Research Hospital, Department of Ophthalmology, Istanbul, Turkey, E-mail: dracakir@gmail.com

Key words: ranibizumab, neovascular age-related macular degeneration, choroidal thickness, ganglion cell complex, optical coherence tomography

Received: December 01, 2017; Accepted: March 13, 2018; Published: March 17 2018 
group. A signed informed consent was obtained from all participants. The study was approved by Local Clinical Research Ethical Committee and carried out in accordance with the Declaration of Helsinki.

In the study process all participants underwent detailed ophthalmic examination including refraction, slit-lamp biomicroscopy, tonometry, fluorescein angiography (FA) and EDI OCT imaging. Classic CNV lesion was determined by using FA and OCT. All patients in the study group were treated with intravitreal ranibizumab $0.5 \mathrm{mg}$ based on an as-needed (PRN) regimen after 3 monthly loading doses. Retreatment criterias were new or persistent fluid on OCT and a loss of 5 ETDRS letters or more. Age, gender, follow up time and total number of injections were all noted. Clinical information including medical history and habits was also recorded. Nonneovascular AMD patients who consulted to our retinaclinic for routine examination were included in the study as the control group.

Patients with the history of chronic ocular diseases such as glaucoma and uveitis, the history of open or closed-globe injury and vitreo-retinal surgery, diagnosis of polypoidal choroidal vasculopathy and retinal angiomatous proliferation, any vascular pathologies of the retina (such as hypertensive retinopathy, diabetic retinopathy, ven occlusion), systemic diseases such as diabetes mellitus, labil hypertension, connective-tissue diseases and any neurodegenerative diseases such as Alzheimer and Parkinsons diaseases were excluded from the study.

OCT images were obtained by spectral-domain OCT (Spectralis; Heidelberg Engineering, Heidelberg, Germany) by a certified operator. The following scan acquisition parameters were required: dense volume scan $\left(30^{\circ} \times 25^{\circ}\right.$, roughly $\left.9 \times 7.5 \mathrm{~mm}\right), 31 \mathrm{~B}$-scans each spaced 244 Mm apart, automatic real-time mean of 20 , high speed (512 A-scans/Bscan). Thickness analysis of retina, retinal nerve fiber layer (RNLF), ganglion cell layer (GCL), internal plexiform layer (IPL) and ganlion cell complex (GCC; [the total of RNLF, GCL and IPL values]) was defined as a mean thickness of the central 1-mm zone of the ETDRS grid and measured by the program embedded in spectral-domain OCT after automatic segmentation of all layers (Figure 1). Due to the fact that CNV lesion deteriorated the retinal layers around the foveal region, automatic segmentation and analysis of retinal layers using software in spectral-domain OCT was not possible. Therefore retinal layers measurement was performed with a distance of $2500 \mu$ to the fovea.

Choroidal images were obtained by spectral-domain OCT with Enhanced Deep Imaging (EDI) mode by the same certified operator. The following scan acquisition parameters were required: dense volume scan $\left(20^{\circ} \times 10^{\circ}\right.$, roughly $\left.6 \times 2 \mathrm{~mm}\right), 25 \mathrm{~B}$-scans each spaced 122 Mm apart, automatic real-time mean of 20, high speed (512 A-scans/Bscan) centering at the fovea. The EDI-OCT images were saved using the automatic averaging and eye tracking system of Spectralis OCT. Subfoveal choroidal thickness (SFCT) was defined as the vertical distance between the outer border of the retinal pigment epitheliumBruch's membrane complex, and the chorioscleral junction. SFCT was measured by using digital calipers provided by the Heidelberg Spectralis OCT software, at the subfoveal region (Figure 2). All the choroidal thickness measurements were performed by two experienced operator independently and they were masked to the patients' information. After analysis process data obtained from both operators were averaged. Before examination blood pressure measurement was
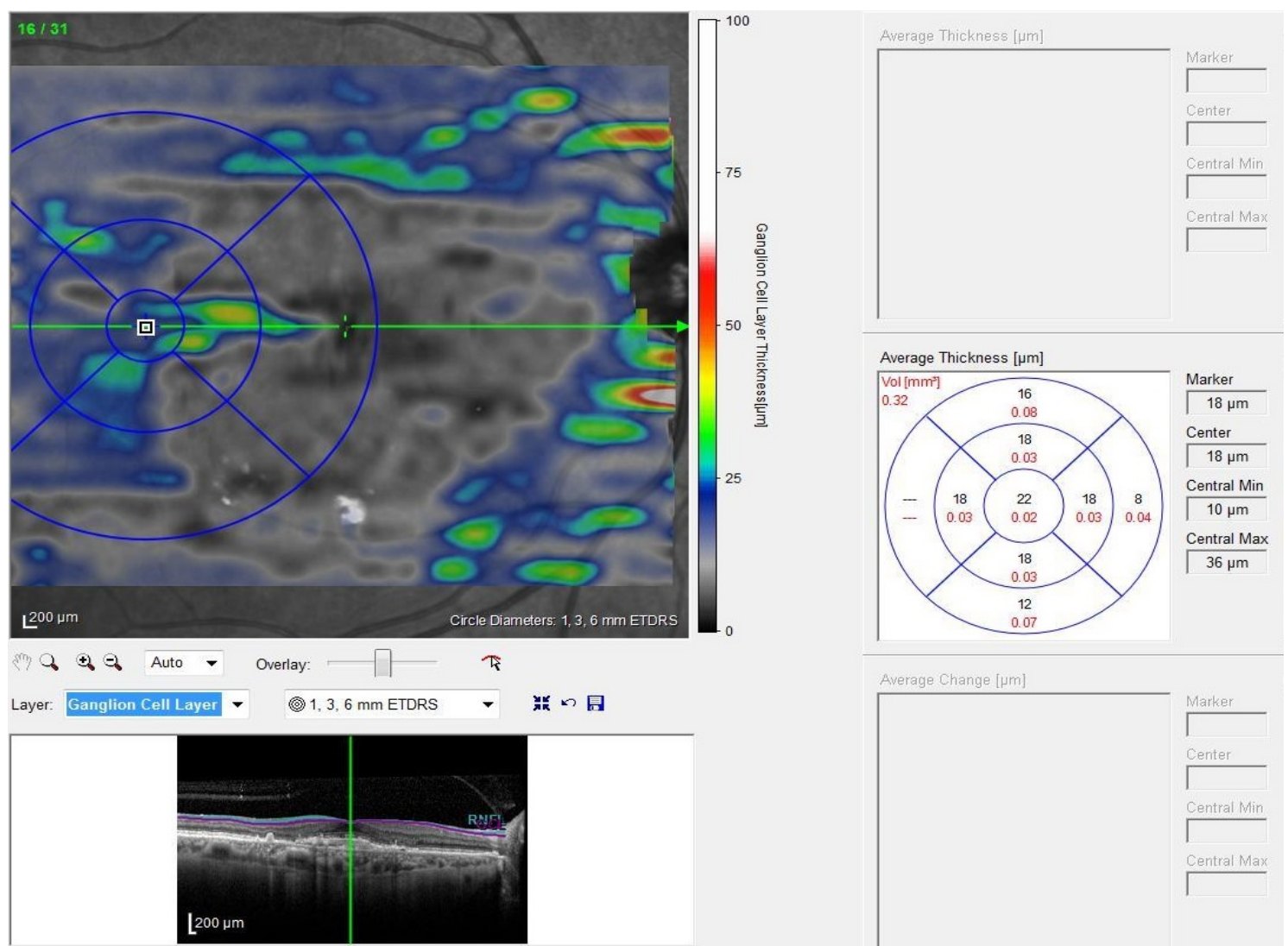

Figure 1. Thickness analysis of GCL. The central 1-mm zone of the ETDRS grid was located to $2500 \mu$ to the fovea. Mean thickness of the central zone was measured automatically by the instrument. 
also performed to all participants due to prevent the effect of systemic arterial hypertension on the choroid. Systemic arterial pressure measurements of all participants were below systolic $135 \mathrm{mmhg}$ and diastolic $85 \mathrm{mmhg}$ at the time of OCT examination. Considering the diurnal variation of choroidal thickness, all OCT images were obtained between $10 \mathrm{AM}$ and $12 \mathrm{PM}$.

Statistical analyses were perfomed using the SPSS software version 21 (SPSS, Chicago, IL, USA). The variables were investigated using visual and analytical methods (Kolmogorov-Simirnov/Shapiro-Wilk's test) to determine whether or not they are normally distributed. The Student's t-test was used to compare normally disributed parameters. Non-parametric tests were conducted to compare the non-normally distributed and ordinal variables. A p-value of less than 0.05 was considered to show a statistically significant result. When investigating the changes in GCC by VEGF theraphy, the effects of gender and age was adjusted using two-way ANOVA and ANCOVA tests, respectively.

\section{Results}

Thirty-two eyes of 27 patients - 9 women (33.3\%) and 18 men $(66.6 \%)$, with a mean age of $76.9 \pm 5.5$ years - constituted the study group. Thirty-one eyes of 17 healthy subjects -9 women (52.9\%) and 8 men $(47.1 \%)$, with a mean age of $74.6 \pm 4.4$ years were included as the control group. All the participants in the study group were treated with intravitreal ranbizumab. The mean ( \pm standart deviation) injection number of the study group was $12.1 \pm 4.0$. The mean follow-up time was $3.6 \pm 1.6$ years. Baseline and demographic characteristics of the study and control group was shown in Table.1.

The mean SFCT values tended to be lower in ranibizumab treated eyes than controls, but difference was not statistically significant (184 $\pm 75.5 \mu$ vs. $200.8 \pm 60.2 \mu ; \mathrm{p}: 0.336$ ). Likewise, the study and control groups' mean retinal thickness values were not statistically significant (250.4 $\pm 29.4 \mu$ vs. $249.7 \pm 15.2 \mu$; p:0.906).

However, the mean GCL, IPL and GCC values of ranibizumab treated eyes were found to be statistically significantly lower than controls $([21.06 \pm 8.03 \mu v$ s. $24.6 \pm 5 \mu$; $: 0.036],[24.5 \pm 7.8 \mu$ vs. 29.8 $\pm 3.8 \mu$; p:0.001], [64.1 $\pm 16.5 \mu$ vs. $72.9 \pm 8.03 \mu ; \mathrm{p}: 0.010]$ respectively). The similar significance was not found in the mean RNLF values of the study and control group $(18.5 \pm 3.8 \mu$ vs. $18.4 \pm 2.5 \mu$; :0.891).The mean values and statistical analyses of retino-choroidal thicknesses of both groups are summarized in Table 2.

Table 1. Demographic characteristics of study and control groups.

\begin{tabular}{|c|c|c|c|}
\hline & Study Group (N=32) & Control Group (N=31) \\
\hline Age (Mean [SD]) & $76.9(5.5)$ & $74.6(4.4)$ & $47.1 \%$ \\
\hline Gender (Male [\%]) & $66.6 \%$ & - \\
\hline Total number of injection & $12.1 \pm 4.0$ & $0.075^{*}$ \\
\hline Follow-up time (years) & $3.6 \pm 1.6$ & - \\
\hline
\end{tabular}

*Student-t test, $* *$ Mann-Whitney $\mathrm{U} ; \mathrm{p}<0.0$

Table 2. Retino-choroidal thickness measurements in both groups.

\begin{tabular}{|c|c|c|c|}
\hline & Study Group (N=32) & Control Group (N=31) \\
\hline Subfoveal choroidal thickness (mean[SD]) & $184 \pm 75.5 \mu$ & $200.8 \pm 60.2 \mu$ \\
\hline Retinal thickness (mean[SD]) & $250.4 \pm 29.4 \mu$ & $249.7 \pm 15.2 \mu$ \\
\hline Ganglion cell layer thickness (mean[SD]) & $21.06 \pm 8.03 \mu$ & $24.6 \pm 5 \mu$ \\
\hline $\begin{array}{c}\text { Internal plexiform layer thickness } \\
\text { (mean[SD]) }\end{array}$ & $24.5 \pm 7.8 \mu$ & $29.8 \pm 3.8 \mu$ \\
\hline Ganglion cell complex thickness (mean[SD]) & $64.1 \pm 16.5 \mu$ & 0.906 \\
\hline RNLF thickness (mean[SD]) & $18.5 \pm 3.8 \mu$ & $72.9 \pm 8.03 \mu$ \\
\hline
\end{tabular}

*Student-t test $\mathrm{p}<0.05$

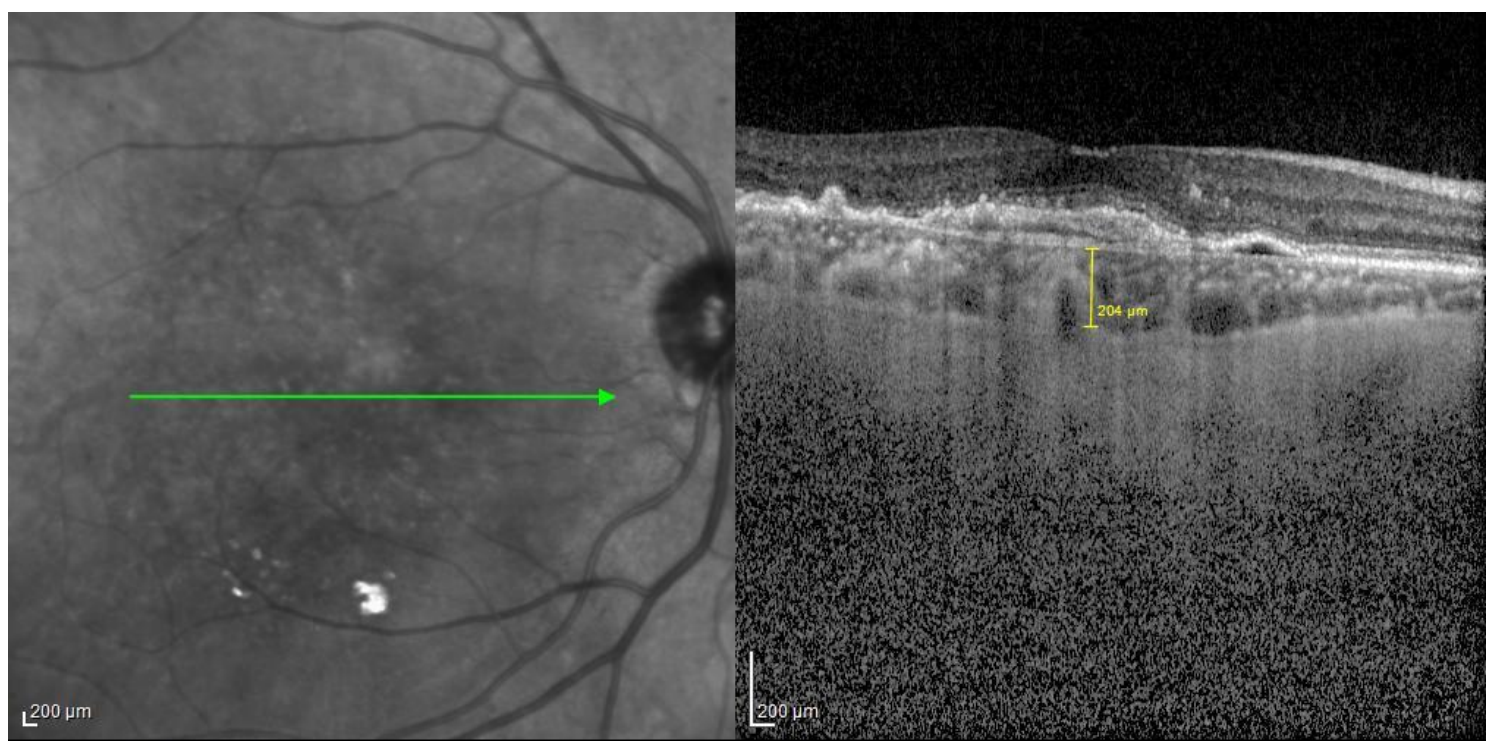

Figure 2. SFCT measurement is seen. 
Spearman's correlation analysis showed a negative but not a statistically significant correlation between injection number or followup time and GCL-IPL-GCC layer thicknesses. In order to eliminate the effect of gender and age on GCL, IPL and GCC layer thicknesses, we have performed two-way ANOVA and ANCOVA tests, respectively. We found that only the anti-VEGF treatment had a statistically significant effect on GCL, IPL and GCC layer thicknesses (p:0.012). Gender and age were not responsible for the changes in the GCL, IPL and GCC layer thicknesses (p:0.732, p:0.744,respectively).

\section{Discussion}

VEGF plays an essential role for the maintanance of retinal neural cells as a neuroprotective agent [20]. The exacerbation of RPE and choroidal atrophy by anti-VEGF theraphy in neovascular AMD has become a current topic [6,9-13]. However, there is a lack of literature about retinal layers and anti-VEGF theraphy. In this study we investigated the long-term effect of intravitreal ranibizumab treatment on the retinal layers' thicknesses. Statistical analyses showed a significant association between the GCL, IPL and GCC thicknesses and intravitreal ranibizumab treatment. Probably, this finding is due to the inhibition of the neuroprotective effect of VEGF-A on apoptosis of retinal neurons. To the best of our knowledge, no prior controlled study has observed such a finding. There is only one study in the literature that has looked at the short term results (after 3 intravitreal injections of ranibizumab administered monthly) of anti-VEGF therapy in humans. In that study the authors emphasized a reduction of GCC thickness but this was not statistically significant [19]. We attribute this finding to the short follow-up time in that study. Someone may also think that intraocular pressure (IOP) fluctuations secondary to intravitreal injections might result in that GCC reduction, however it was shown in several studies that IOP spikes are limited to within the first few minutes of the injection procedure [18,21]. Surely, such peaks may have even induced GCC thinning, in time.

Interestingly, we did not find a significant association between RNLF and anti-VEGF treatment. This is an unexpected result for us. But we consider that the ganglion cells or IPL might be affected primarily and over time damage may progress to RNLF as in the glaucoma pathogenesis. A similar result was also reported by ElAshry et al. The authors looked at the RNLF thickness in neovascular AMD patients receiving ranibizumab injections and demonstrated no harmful effect of intravitreal ranibizumab on RNLF thickness in the short term [17]. Conversely, Martinez-de-la-Casa et al. found a significant RNLF thinning after 12 months of follow-up [18]. Another issue is how the function of the ganglion cells are being affected by that thinning. Nishimura et al. examined retinal ganglion cell function using the photopic negative response of the electroretinogram in patients with AMD and they found that retinal ganglion cell function was not altered by repeated intravitreal ranibizumab injection [22]. Results of an another study conducted by Zayit-Soudry et al. showed that the repeated intravitreal injections of ranibizumab or bevazicumab have no cumulative long-term effect on the retina in rabbits [23]. On the contrary, Nishijima et al. observed a significant loss of retinal ganglion cells in normal adult animals under chronic inhibition of VEGF-A [24]. It seems that further prospective randomized trials are needed on this subject.

There were conflicting results in the literature about the changes in choroidal thickness during anti-VEGF theraphy for neovascular AMD [14,16,25]. Ting et al. reported a significant reduction in SFCT after anti-VEGF theraphy in typical AMD, and the authors added that choroidal thickness changes were similar despite differences in number of anti-VEGF injections [14]. Mc Donnell et al. showed a reduction in choroidal thickness over time in eyes with neovascular AMD but they emphasized that anti-VEGF theraphy did not appear to accelerate this decline [16]. Conversely, Rahman et al. did not find a reduction in SFCT in neovascular AMD patients, however, the study sample size was small with a shorter follow-up period [25]. In our study, although we observed lower SFCT values in the ranibizumab treated eyes than nonneovascular patients, this difference was not statistically significant. Our study sample size may have hindered this significance. Since VEGF-A plays an essential role in the survival of choroidal vascular plexus, choroidal thinning will not be an unexpected outcome. Nonetheless, one should keep in mind that the choroidal thickness measurements may be frequently affected by unrecognized systemic conditions.

The main limitation of our study is that it is a not prospective cohort study. We have performed two-way ANOVA and ANCOVA tests in order to eliminate the effect of gender and age on GCL, IPL and GCC layer thicknesses. Although we have found that gender and sex were not responsible for the changes in the GCL, IPL and GCC layer thicknesses, our results may have been influenced by some other unpredictable factors. Additionally, we have not performed any tests such as multifocal electroretinogram or microperimetry to evaluate the functional outcomes of this thinning in that layers.

\section{Conclusion}

In conclusion, our study showed that long-term intravitreal ranibizumab treatment was associated with significant reduction in the GCL, IPL and GCC thicknesses. When we consider the limitations of this study, randomized prospective studies must be conducted to determine if any difference exits between anti-VEGF agents or if this thinning induces any damage in the function of the retinal ganglion cells.

\section{Declarations}

\section{Ethics approval and consent to participate}

The study was approved by Local Clinical Research Ethical Committee and carried out in accordance with the Declaration of Helsinki.

\section{Availability of data and material}

The datasets used and/or analysed during the current study are available from the corresponding author on reasonable request.

\section{Authors' contributions}

AC designed the study, analyzed and interpreted the patient data, SKS made contribution to acquisition of data and was a major contributer in writing the manuscript. ED made contribution to acquisition of data and analyzed the patient data, AA was a contributer in writing the manuscript and revised it. MHU involved in drafting the manuscript and revising it.

\section{References}

1. Gangnon RE, Lee KE, Klein BE, Iyengar SK, Sivakumaran TA, et al. (2015) Severity of age-related macular degeneration in 1 eye and the incidence and progression of agerelated macular degeneration in the fellow eye: the Beaver Dam Eye Study. JAMA Ophthalmol 133: 125-132. [Crossref]

2. Rofagha S, Bhisitkul RB, Boyer DS, Sadda SR, Zhang K; SEVEN-UP Study Group (2013) Seven-year outcomes in ranibizumab-treated patients in ANCHOR, MARINA, and HORIZON: a multicenter cohort study (SEVEN-UP). Ophthalmology 120: 22922299. [Crossref] 
3. Gillies MC, Campain A, Barthelmes D, Simpson JM, Arnold JJ, et al. (2015) LongTerm Outcomes of Treatment of Neovascular Age-Related Macular Degeneration: Data from an Observational Study. Ophthalmology 122: 1837-1845. [Crossref]

4. Comparison of Age-related Macular Degeneration Treatments Trials (CATT) Research Group, Martin DF, Maguire MG, Fine SL, Ying GS, et al. (2012) Ranibizumab and bevacizumab for treatment of neovascular age-related macular degeneration: two-year results. Ophthalmology 119: 1388-1398. [Crossref]

5. Rosenfeld PJ, Shapiro H, Tuomi L, Webster M, Elledge J, Blodi B (2011) Characteristics of patients losing vision after 2 years of monthly dosing in the phase III ranibizumab clinical trials. Ophthalmology 118: 523-530. [Crossref]

6. Grunwald JE, Pistilli M, Ying GS, Maguire MG, Daniel E, Martin DF (2015) Growth of geographic atrophy in the comparison of age-related macular degeneration treatments trials. Ophthalmology 122: 809-816. [Crossref]

7. Maharaj AS, Walshe TE, Saint-Geniez M, Venkatesha S, Maldonado AE, et al. (2008) VEGF and TGF-beta are required for the maintenance of the choroid plexus and ependyma. J Exp Med 205: 491-501. [Crossref]

8. Saint-Geniez M, Kurihara T, Sekiyama E, Maldonado AE, D'Amore PA (2009) An essential role for RPE-derived soluble VEGF in the maintenance of the choriocapillaris. Proc Natl Acad Sci U S A 106: 18751-18756. [Crossref]

9. Grunwald JE, Daniel E, Huang J, Ying GS, Maguire MG, Toth CA, et al. (2014) Risk of geographic atrophy in the comparison of age-related macular degeneration treatments trials. Ophthalmology 121: 150-161. [Crossref]

10. Xu L, Mrejen S, Jung JJ, Gallego-Pinazo R, Thompson D, Marsiglia M, et al. (2015) Geographic atrophy in patients receiving anti-vascular endothelial growth factor for neovascular age-related macular degeneration. Retina 35: 176-186. [Crossref]

11. Channa R, Sophie R, Bagheri S, Shah SM, Wang J, Adeyemo O, et al. (2015) Regression of choroidal neovascularization results in macular atrophy in anti-vascular endothelial growth factor-treated eyes. Am J Ophthalmol 159: 9-19.e1-2. [Crossref]

12. Lois N, McBain V, Abdelkader E, Scott NW, Kumari R (2013) Retinal pigment epithelial atrophy in patients with exudative age-related macular degeneration undergoing antivascular endothelial growth factor therapy. Retina 33: 13-22. [Crossref]

13. Young M, Chui L, Fallah N, Or C, Merkur AB, Kirker AW, et al. (2014) Exacerbation of choroidal and retinal pigment epithelial atrophy after anti-vascular endothelial growth factor treatment in neovascular age-related macular degeneration. Retina 34: 13081315. [Crossref]
14. Ting DS, Ng WY, Ng SR, Tan SP, Yeo IY, Mathur R, et al. (2016) Choroidal Thickness Changes in Age-Related Macular Degeneration and Polypoidal Choroidal Vasculopathy: A 12-Month Prospective Study. Am J Ophthalmol 164: 128-36.e1. [Crossref]

15. Koizumi H, Kano M, Yamamoto A, Saito M, Maruko I, Kawasaki R, et al. (2015) Short-term changes in choroidal thickness after aflibercept therapy for neovascular agerelated macular degeneration. Am J Ophthalmol 159: 627-633. [Crossref]

16. McDonnell EC, Heussen FM, Ruiz-Garcia H, Ouyang Y, Narala R, et al. (2014) Effect of anti-VEGF treatment on choroidal thickness over time in patients with neovascular age-related macular degeneration. Eur J Ophthalmol 24: 897-903. [Crossref]

17. El-Ashry MF, Lascaratos G, Dhillon B. Evaluation of the effect of intravitreal ranibizumab injections in patients with neovascular age related macular degeneration on retinal nerve fiber layer thickness using optical coherence tomography. Clin Ophthalmol. 2015;9:1269-74. [Crossref]

18. Martinez-de-la-Casa JM, Ruiz-Calvo A, Saenz-Frances F, Reche-Frutos J, CalvoGonzalez C, et al. (2012) Retinal nerve fiber layer thickness changes in patients with age-related macular degeneration treated with intravitreal ranibizumab. Invest Ophthalmol Vis Sci 53: 6214-6218. [Crossref]

19. Perdicchi A, Peluso G, Iacovello D, Balestrieri M, Delle Fave M, et al. (2015) Ganglion Cell Complex Evaluation in Exudative Age-Related Macular Degeneration after Repeated Intravitreal Injections of Ranibizumab. Biomed Res Int 268796.

20. Storkebaum E, Lambrechts D, Carmeliet P (2004) VEGF: once regarded as a specific angiogenic factor, now implicated in neuroprotection. Bioessays 26: 943-954. [Crossref]

21. Falkenstein IA, Cheng L, Freeman WR (2007) Changes of intraocular pressure after intravitreal injection of bevacizumab (avastin). Retina 27: 1044-1047. [Crossref]

22. Nishimura T, Machida S, Harada T, Kurosaka D (2012) Retinal ganglion cell function after repeated intravitreal injections of ranibizumab in patients with age-related macular degeneration. Clin Ophthalmol 6: 1073-1082.

23. Zayit-Soudry S, Zemel E, Loewenstein A, Perlman I (2010) Safety evaluation of repeated intravitreal injections of bevacizumab and ranibizumab in rabbit eyes. Retina 30: 671-681. [Crossref]

24. Nishijima K, Ng YS, Zhong L, Bradley J, Schubert W, et al. (2007) Vascular endothelia growth factor-A is a survival factor for retinal neurons and a critical neuroprotectant during the adaptive response to ischemic injury. Am J Pathol 171: 53-67. [Crossref]

25. Rahman W, Chen FK, Yeoh J, da Cruz L (2013) Enhanced depth imaging of the choroid in patients with neovascular age-related macular degeneration treated with anti-VEGF therapy versus untreated patients. Graefes Arch Clin Exp Ophthalmol 251: 1483-1488. [Crossref]

Copyright: $(02018$ Cakır A. This is an open-access article distributed under the terms of the Creative Commons Attribution License, which permits unrestricted use, distribution, and reproduction in any medium, provided the original author and source are credited. 